\title{
Research on Monitoring Methods of Landslide Based on a Demonstration Project in Zhejiang Province, Southeast of China
}

\author{
Mo-Mo ZHI', Pan PAN, Zhen-Lei WEI \\ Department of Civil Engineering, Zhejiang University, Yuhangtang RD. 866, 310058, Hangzhou, \\ China \\ zmm@zju.edu.cn \\ ${ }^{*}$ Corresponding author
}

Keywords: Landslide, Monitoring Method, Disaster Prediction.

\begin{abstract}
Landslide monitoring is a fundamental work for landslide hazard prediction and landslide treatment. The quality monitoring work will affect the correctness of the decision for disaster prevention. Base on the development of landslide monitoring technology in Zhejiang Province, the paper introduces the monitoring scheme and the prediction technical research and development, and summarizes the characteristic of several methods for monitoring, and looks forward to the direction of future work.
\end{abstract}

\section{Introduction}

China is one of worst landslide disaster countries in the world, and annual economic losses caused by landslide at about 20 billion [1]. Research concerning rainfall infiltration mechanisms as well as the influences on stability in unsaturated soil slopes has been investigated through field monitoring programs [2-5]. Design of landslide hazard prediction and control should be done after obtaining the dynamic characteristics of the landslide. So the landslide monitoring is foundational work both for the treatment and prediction of the landslide. Monitoring quality will affect the correctness of the decision for disaster prevention.

Zhejiang province is located in Southeast China in a sub-tropical region, and 70.4 percent of the province is mountainous or hilly. There are more than 4200 landslide hazards and potential hazard points in the province ${ }^{[6]}$.The professional geological hazard monitoring in Zhejiang Province was carried out for many years, but the monitoring methods and technical are still single and relatively backward, and sometimes we could not obtain the monitoring information in time. There were not enough technicians mastered monitoring methods. In view of the current development of landslide monitoring technology in Zhejiang Province, we carried out a monitoring demonstration project in Xiashan village landside from Jul 2007 to Jun 2013, used a variety of advanced monitoring methods, compared advantages and disadvantages of various techniques of landslide monitoring, studied the monitoring technology which are suitable for Zhejiang province, established a landslide hazard prediction and decision support system for disaster prevention. Trough the demonstration project, we enhance the level of landslide monitoring and disaster prevention of landslide and improve protection of lives and property.

\section{Project Description}

Xiashan village landside located in Zhejiang province and is the biggest rainfall-induced landslide [7, 8] in the Province, the volume of the slide is about 8.25 million $\mathrm{m} 3$ with an affected area of almost 252,000 m2. The slope is of a chair-shaped form. Quaternary residual colluvium overlies the Pliocene sedimentary and basalt layers. The landslide shows slowly, uninterruptedly sliding at present. It is located approximately $250 \mathrm{~m}$ to the east of Shimen Reservoir and minimum $152 \mathrm{~m}$ above it (Fig.1). The complete instability of the slide mass will probably generate a potentially destructive seiche in the reservoir, which is a huge threat to the local villagers. There 
were 2 obvious sliding since 1958. The slope mass moved to west suddenly due to typhoon rainstorm in July 30th,1989 and slid again several days after the heavy rain in July 6th,2001.
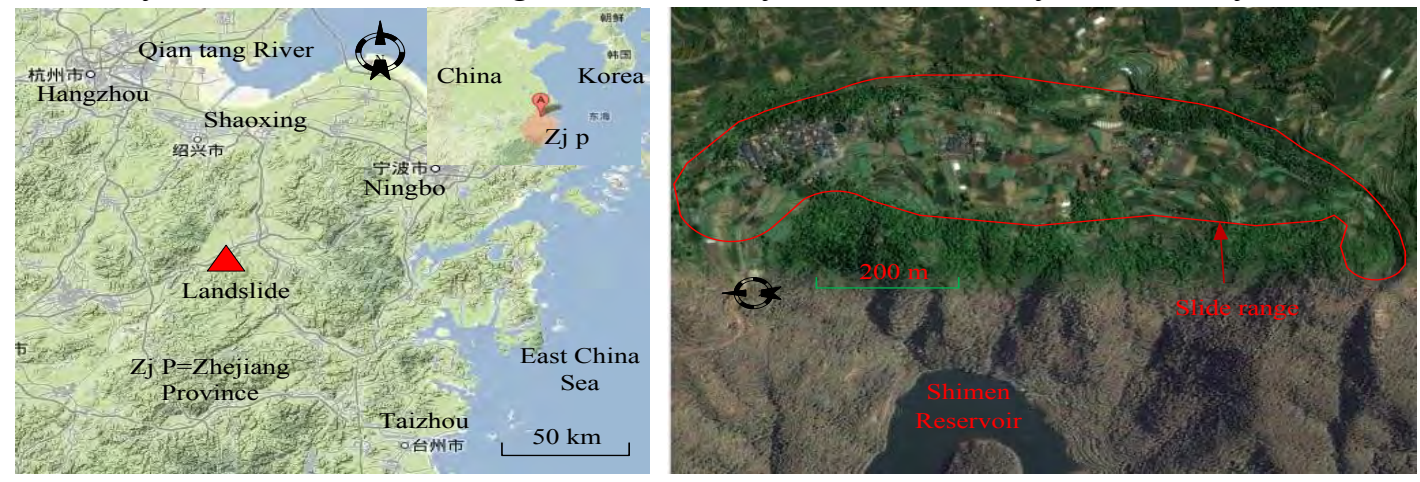

Fig. 1 The Location of the Study Area (the satellite image is obtained from Google map)

The landslide had good geological data and preliminary monitoring data, and was suitable for a variety of application test on dynamic monitoring methods of landslide.

\section{Monitor System}

The pilot test program includes GPS, total station ground movement measurement, laser distance measurement, video monitoring, inclinometer of fixed types, precipitation and groundwater level measurement.

As shown in Figure 2, there are 4 GPS monitoring points (points s2, t3, t4, w3) 25 Total station monitoring points along 7 profiles (profiles s, p, t, v, w, x, y), 6 sets ranging laser, video monitoring system, 2 fixed inclinometer boreholes (points $\mathrm{t} 3$ and $\mathrm{t} 4$ ) and 4 hydrographic holes ( 2 holes at point t3 and 2aholes at point t4) along B-B' profile in the landslide area, while we installed automatic udometer and crack meter (point $\mathrm{M}$ ) for precipitation measurement and crack extended monitoring.

Monitoring data indicates the landslide is in a process of low rate of deformation. The monitoring system could record effectively the deformation of the landslide. There is an active correlation of precipitation and groundwater level, and the displacement rate is closely related to the groundwater level.

\section{Research and Technical Line}

\section{Research on Monitoring Methods}

Propose economic and effective landslide monitoring methods based on the geological characteristic of landslide disasters, and analyze the applicability of monitoring instruments, and summarize the advantages and disadvantages of the various methods of monitoring.

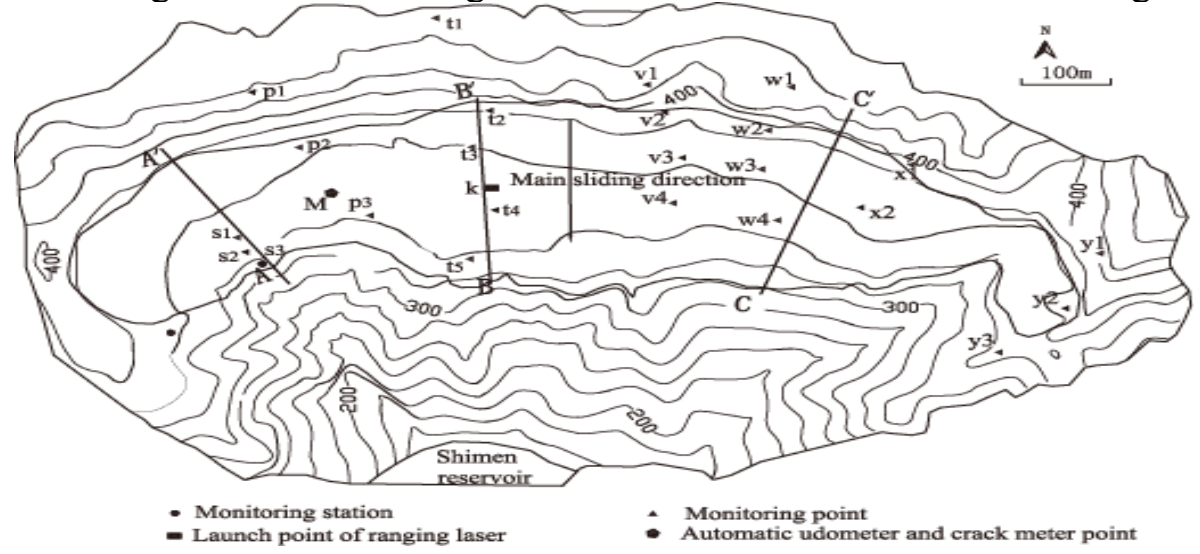

Fig. 2 Geological Map of the Landslide Area and Distribution of the Monitoring Points 
Trough the research on summarizing the current methods at home and abroad, we discuss the reasonable monitoring proposal for various landslides under different geological conditions, solve a. method that determining the monitoring grade, b. principles that selecting monitoring variables, $\mathrm{c}$. designation of landslide monitoring system.

The monitoring environment is usually very bad for the instrument and equipment. In addition to satisfy technical performance and functionality for monitoring requirements, the instruments should have high reliability, high stability, low maintenance requirements, suitable for buried installation and other features. Through analyzing different types of landslide monitoring equipment, methods and system at home and abroad, we evaluate the applicability of different instrument, provide technical guidance for safety monitoring of landside disaster, a. conditions of using various monitoring instruments, $b$. the accuracy of various monitoring instruments c. long-term stability of different monitoring instrument and the costs, $d$. the technical requirements for the installation and maintenance.

\section{Research on the Methods for Analyzing Monitoring Data}

In order to obtain the regularity or tendency of the landslide failure quickly and effectively, we need to analyze the monitoring data timely and correctly, and the workload is huge if dependent on hand-finishing. However sometimes it's difficult to analyze the data owing to the independence or the huge quantity of monitoring data, and the analysis on monitoring data is limited to variation tendency of cracks, the displacement of monitoring points, precipitation in the landslide area or the groundwater level and so on.

In view of the current situation in landslide monitoring in Zhejiang Province, we do research to solve the problems below, a. develop a processing system to collect, analyze and interpret the monitoring data and information rapidly, $b$. analyze the size source and type of the error of the instruments and equipment set in XiaShan village landslide area base on reliability test and error analysis, and propose reasonable method to handle and amend the data. c. realize the process of analyzing and illustrating the database monitoring data $\mathrm{d}$. construct a data processing platform to realize qualitative and quantitative analysis and comprehensive utilization on the data, master regularity of the slope failure, predict the tendency of the landslide development and analyze the relationship between the landslide deformation and environmental factors.

Research on the method of prediction and forecast

From qualitative to quantitative prediction of geological hazards is an important direction for landslide disaster prevention. It's difficult to describe landslide disasters quantitatively using a unified model because there are many control factors during the development of different disasters, and the key trigger factor may vary for different disasters, at the same time disasters occur random in space and time. The forecast models can be divided into two major categories. One is based on the phenomenon of slope failure analysis, conclusion got by the method is qualitative and require forecaster have a wealth experience. The other one is model theory, it's a quantitative prediction model based on the time series data of characteristic parameters of slope deformation, and use mathematical model to extrapolate the failure deformation of the slope. Model theory is an important component of the slope monitoring. Current instability model always fail to meet forecast requirement of environmental factors such as precipitation changes.

During the research we solve several main problems, a. analyze the dynamic deformation when the environmental conditions change smaller using single-factor ARMA model, $b$. analyze the dynamic deformation caused by precipitation and groundwater level based on matrix form of ARMA model using multivariate time series, c. establish landslide time forecast model based on the timing curve and the factor of precipitation-induced.

\section{Visual Management of Monitoring Data and Decision Support System for Disaster Prevention}

In order to make sure the visual dynamic information display and decision support system work for the managers and decision makers, we establish landslide monitoring database based on GIS platform. The system is based on geological hazard assessment of landslides and uses advanced GIS techniques. Trough powerful graphical display, general process of information, geographic search 
queries and spatial analysis, the system can provide the result of output queries and analysis in the form of graphics and intuitive charts to the managers and decision makers. The framework of the system is shown in Figure 3, data transmission and analysis of the real-time slope monitoring system is based on GPRS wireless internet, and release of network information is based on WebGIS.

Work during the construction of the project is shown as below. a. Design a web page as browser window for information of landslides, monitoring methods and typical geological hazards. b. Construct the management and query system, complete landslide information management analysis and query display based on internet networking platform. c. Establish a remote real-time system for monitoring data dynamic transmission and analysis based on GPRS wireless internet. The system can issue orders to control the remote monitoring sensors distributed in the landslide area trough GPRS. It can complete the monitoring action and the real-time transmission of the monitoring data. d. Develop functional modules such as terrain analysis, virtual landscape analysis, and decision by comprehensive evaluation, prediction of deformation and stability analysis. f Develop system of integrated model analysis and decision making, the system effectively couple all the modules and achieve comprehensive model analysis and evaluation or decision by analyzing space geographic data, factors affecting stability, and safety monitoring information.

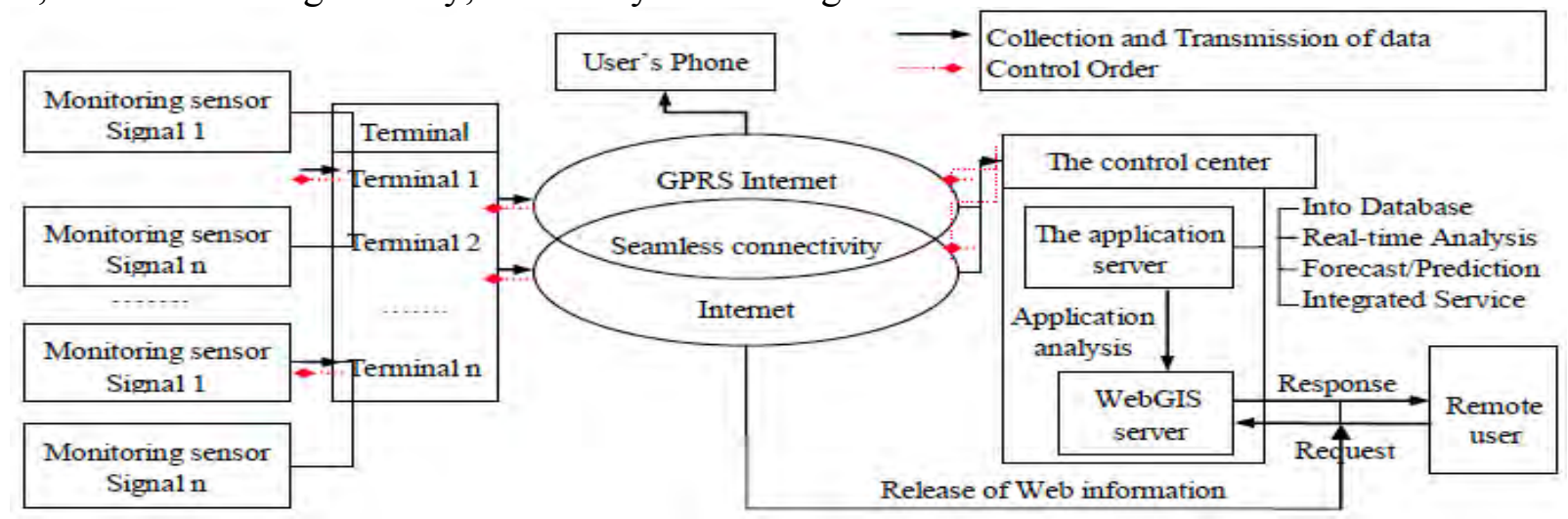

Fig. 3 The Framework of Visual Management of the Monitoring Data and the Decision Support System

\section{Conclusion}

\section{Analysis of Monitoring Methods}

Automatic monitoring of total station chooses measuring robot TCA2003, it's intelligent and has high speed and high precision. The method is considered as one of the monitoring methods and also as a mean of checking other monitoring techniques. The monitoring points must maintain visibility and with monitoring distance increased the accuracy declined. The equipment cost is also high.

GPS monitoring stations needn't to maintain visibility, and trough the method we can get three dimensional displacements simultaneously. Round -the clock observation makes the implement of system automation easy. The accuracy could reach $\mathrm{mm}$ level and we can get effective displacement of the landslide. However the freedom of choosing points is lower.

The advantages of inclinometer are high precision, reliable performance, good stability and easy to get data. Inclinometer in monitoring deformation of rock and soil slope by drilling boreholes has a great vantage. In current condition, the method is limited by the accuracy and deformation phrases owing to the limitation of instrument. It's suitable for slow steady deformation phrase. The inclinometer will not work properly when the borehole has severe deformation or has local emergency. We take fixed type inclinometer in the project, the sensor can't be set very dense along the borehole owing to cost, and this has influence on measurement accuracy.

\section{Progress of Work}

On the base of summarizing current monitoring method at home and abroad, we construct the demonstration project, build a real-time remote monitoring system, compare the characteristic of 
various monitoring methods and discuss the reasonable geological landslide monitoring program under different condition. Do research on forecast and prevention methods by comprehensive analysis of monitoring data. Complete visualized management of monitoring data and develop the decision support system for disaster prevention.

\section{Acknowledgment}

The study is supported by the National "Twelfth Five-Year" Plan for Science \& Technology Support (No.2012BAK10B06).

\section{References}

[1]R. Q. Huang (2007) Large-scale landslides and their sliding mechanisms in China since the 20th century, J. Chinese Journal of Rock Mechanics and Engineering. 26(3): 433-454 (in Chinese with English abstract).

[2]Smethrust JA, Clarke D, Powrie W (2006) Seasonal changes in pore water pressure in a grasscovered cut slope in London clay. Geotechnique 56(8):523-537.

[3]Liang WL, Kosugi K, Mizuyama T (2007) Heterogeneous soil water dynamics around a tree growing on a steep hillslope. Vadose Zone J 6(4):879-889.

[4]Tu XB, Kwong AKL, Dai FC, Tham LG, Min H (2009) Field monitoring of rainfall infiltration in a loess slope and analysis of failure mechanism of rainfall-induced landslides Engineering Geology 105(1-2):134-150.

[5]Pagano L, Picarelli L, Rianna G, Urciuoli G (2010) A simple numerical procedure for timely prediction of precipitation-induced landslides in unsaturated pyroclastic soils. Landslides 7(3):273289.

[6]Statistical Yearbook of China (SYC) (2011) The State Statistical Bureau, Beijing (in Chinese)

[7]Yu, B. T., Sun, H. Y. (2006) Characteristics and stability analysis of xiashan landslide in Zhejiang province. Chinese Journal of Rock Mechanics and Engineering, 25(Supp.1) 2875-2881 (in Chinese with English abstract).

[8]Zhao, Q. L, Sun, H. Y. (2012) Influence of confined water on translational landslide. Chinese Journal of Rock Mechanics and Engineering, 31(4) 762-769 (in Chinese with English abstract). 